\title{
Chapter 10 \\ Pay-To-Pass: Evolving Online Systems That Undermine the Integrity of Student Work
}

\author{
Nancy Chibry (i) and Ebba U. Kurz $\mathbb{D}$
}

\begin{abstract}
In an age where information is available at our fingertips, students in the post-secondary environment have equally ready access to resources that can be supportive of their academic development or academically questionable. In this chapter, we describe the pervasiveness of pay-to-pass websites in the Canadian postsecondary context. We distinguish pay-to-pass websites from other forms of contract cheating by defining them as sites encouraging students to share and access course material, assessments, and notes for academic and personal gain, as well as those providing real-time academic support. This chapter is a reflection on the nature and impact of these sites and explores a three-pronged approach to addressing the challenges posed by them on the upholding of academic integrity in post-secondary education.
\end{abstract}

Keywords Academic integrity $\cdot$ Canada $\cdot$ Contract cheating $\cdot$ File-sharing $\cdot$ Internet

The vast majority of university students today have never known life without the internet, and they have been taught to use it as the first source of information whenever a question arises. Technology is pervasive in their lives; as of 2018, 97.9\% of Canadians aged 15-24 reported having a smartphone (Statistics Canada, 2019). Accustomed to connecting and sharing through social media and websites, Dyer (2010) refers to this generation as one living in an "age of collaboration" (p. 172). While some have viewed this as the democratization of knowledge, stripping universities of the role they have held for centuries, the proliferation of for-profit (pay-to-pass) websites for information and file sharing among university students has created an ecosystem or "sharing economy" (Richardson, 2015, p. 121) where knowledge has

\footnotetext{
N. Chibry $(\bowtie) \cdot$ E. U. Kurz $(\varangle)$

University of Calgary, Calgary, Canada

e-mail: n.chibry@ucalgary.ca

E. U. Kurz

e-mail: kurz@ucalgary.ca
}

S. E. Eaton and J. Christensen Hughes (eds.), Academic Integrity in Canada, 
become an accessible commodity_-for a price_eroding the foundation of academic integrity.

There is limited academic literature describing pay-to-pass websites and their impact on academic misconduct in the post-secondary context. Rogerson (2014) and Rogerson and Basanta (2016) recognized that these websites evolved conceptually from those developed to illegally share music and entertainment. They examined student motivation in using these sites (Rogerson, 2014; Rogerson \& Basanta, 2016). Lieneck and Esparza (2018), in the context of a healthcare administration course, determined that $67 \%$ of students used online or social media tools outside the course learning management system to help with their work (Lieneck \& Esparza, 2018).

In this chapter, we define pay-to-pass websites as those through which students upload and access course material, including past assessments, labs and class notes, for academic or personal advantage, as well as those offering online, instant access to 'experts' offering real-time academic support; often both of these features are offered. These sites represent a distinct subtype of contract cheating, a venue for "collaborative cheating" (Harrison et al., 2020, p. 2), which differs from vendors and web services through which students pay to have someone write their paper or take their tests. Among the most common in the Canadian context are Course Hero (coursehero.com), OneClass (oneclass.com), Studocu (studocu.com) and Chegg (chegg.com). This chapter is a reflection on the nature and impact of these sites in the context of our experiences as faculty administrators responsible for investigating allegations of academic misconduct amongst undergraduate students in our respective faculties at a Canadian post-secondary institution (University of Calgary). In addition, the chapter explores approaches that can be taken to address the challenges posed by these websites on the upholding of academic integrity in post-secondary education.

\section{Questionable Practices and Big Profits}

Pay-to-pass websites are big business. In late 2020, Course Hero was valued at $\$ 1.1$ billion (US) (Mascarenhas, 2020), while in early 2021 Chegg's market value reached US\$12 billion (Adams, 2021). Access to the content or services offered through these websites occurs primarily in two ways: by monthly (or yearly) subscription, or by students earning credits for uploading course materials, reminiscent of a barter economy. Some sites, including oneclass.com, offer a rewards and 'refer a friend' program, thereby incentivizing participation beyond the allure of academic gain (Share Notes, Get Rewarded, n.d.). In marketing to students, the sites promise better grades, reduced stress, and ready, round-the-clock access to personalized learning support. In some cases, sites offer scholarships (Course Hero-Scholarships, n.d.) and the quality of the service provided is backed by a guarantee that users will see improved grades (How Does the Better Grades Guarantee Work?, n.d.). Whether reflective of a perceived efficiency gain, time mismanagement or financial incentive (Amigud \& Lancaster, 2019; Park, 2003), these promises are alluring. Using terms 
such as 'community', 'support' and 'collaboration', these companies create a façade that 'sharing is caring' in an academic context. Indeed, recent studies have identified that, compared to the view of instructors, students perceive these websites as far less problematic or dishonest and regard them as akin to unauthorized group work (Eaton et al., 2019; Harrison et al., 2020).

Using paid campus representatives, many of these sites market directly to students by gaining unauthorized access to course email distribution lists or by persistent text message-based marketing campaigns. The former typically occurs by bartering with a student by promising access to the site's resources in exchange for a copy of the class contact list from the course learning management system, even when this is in violation of campus information technology policies (New Policy for Acceptable Use of Electronic Resources \& Information, 2019). The latter occurs after students initially register on a site, after which they receive persistent (often many times daily) text message reminders to upload documents or to return to the site. This is in violation of Canadian federal anti-spam legislation. In September 2020, the Canadian Radio-Television and Telecommunications Commission (CRTC), the federal tribunal charged with implementing laws and regulations pertaining to broadcasting and telecommunications, fined the parent company of oneclass.com for violations related to the use of unsolicited commercial electronic messages sent to Canadian post-secondary students between 2016 and 2020 (Government of Canada and the Canadian Radio-television and Telecommunications Commission (CRTC, 2020)). Together with their savvy marketing strategies, these companies have been diligent in ensuring their fine print indicates that students are expected to contribute and use resources in a manner consistent with their institutional academic integrity policy, essentially relieving the company from any culpability by transferring the burden of responsibility squarely onto their users. However, like many social media sites, most pay-to-pass sites do not review posted content, and only remove copyrighted content when a complaint is filed (Kolowich, 2009). Indeed, in our experience, many of these websites are responsive to faculty requests for removal of copyrighted information that has been posted by a user; however, this approach places the burden upon the instructor to monitor and report the uploading of protected course content.

In an effort to gain access to course material for their users, some pay-to-pass sites have also used questionable tactics to engage graduate teaching assistants. In early 2019 at the University of Calgary, under the apparent guise of a job interview for an online 'teaching opportunity', graduate students with experience as course teaching assistants were asked to share course material. It was only after realizing that no job was available, but course materials had been surrendered, that the graduate students recognized that they had been duped. Deceptively, the interviews were held on campus in space rented at the University's teaching and learning hub, perhaps as an attempt to underscore or obscure the illegitimacy of the opportunity (What Is "Pay to Pass"?, 2019).

Pay-to-pass companies have not only focused on attracting student users, but they aim to legitimize their approach through faculty recruitment (Lederman, 2020). Course Hero holds an annual education summit, provides educational grants, and invites faculty to join their faculty club, which is now over 30,000 members strong 
(Lederman, 2020). Course Hero also encourages faculty members to create and share study resources online as a way to support student learning and earn extra income (Help More Students, Earn Extra Income with Educator Exchange (Beta), n.d.), further feigning legitimacy and blurring the lines for students. Despite longstanding concerns about pay-to-pass sites, it is remarkable that they have entered into agreements with post-secondary institutions. In 2019, Purdue University joined forces with Chegg to integrate Chegg writing tools into the university's Online Writing Lab (Purdue News Service, 2019). These efforts are not without detractors (Purdue Professors Criticize Writing Partnership with Chegg, n.d.), and we are left to wonder what message this sends to post-secondary students who may view this as an endorsement of the totality of Chegg's offerings.

\section{Prevalence in the Canadian Context}

Among the earliest public descriptions of the incursion of pay-to-pass sites in the Canadian context was a 2014 article in the Ryerson University student newspaper, describing a professor's discovery of class notes on OneClass (Nemers, 2014). Since that time, there has been an explosion of websites offering students the opportunity to access completed assessments, class notes or expert assistance. It is challenging to quantify the penetrance of pay-to-pass services into the Canadian post-secondary sector. While there has been a documented increase in the use of contract cheating sites amongst Canadian post-secondary students between 2006 and 2018 (Clarke \& Lancaster, 2006; Lancaster, 2018), no quantitative data have been published regarding rates of use of pay-to-pass sites. Nevertheless, posters advertising their services abound on university walls and social media campaigns flaunt the services. Some of these sites proudly boast of the size of their document repositories. In April 2019, when we presented at the Canadian Symposium for Academic Integrity (Chibry \& Kurz, 2019), the oneclass.com repository for Western University was 90,000 documents, while McMaster University and York University were 60,000 each. As of November 2020, oneclass.com claimed to have over 105,000 documents available for classes at Western University, and over 70,000 each for McMaster University, York University and the University of Toronto St. George campus. Thus, over the course of 18 months, the repositories for each university grew by almost $17 \%$. Perhaps reflective of their influence, the marked growth in the size of their document repositories suggest a similarly concerning rise in their use.

Although many of these websites have offered services to students for more than a decade, faculty across the country remain largely unaware of their presence. This was illustrated clearly in a live demonstration we held during a session at the 2019 Canadian Symposium on Academic Integrity (Chibry \& Kurz, 2019). We invited a faculty member in the audience to share his university name and course number. Searching on Course Hero, he was shocked to discover both completed labs and copies of past exams posted for his engineering course. He, and many others in the audience, were unaware that such items were in circulation and so readily found. 
As faculty administrators with responsibility for investigating potential breaches in academic integrity, we have observed an increase in student use of these sites in recent years. In some cases, students have submitted laboratory or course assignments bearing the answers to a preceding year's questions, leaving an obvious trail for the grader of the work. In other cases, students are identified by chance when documents still bearing their names or university identification numbers appear on a pay-to-pass website. While the former can be managed through existing academic misconduct procedures, the latter does not carry with it the same evidence of wrongdoing as required by many post-secondary academic misconduct policies. Nevertheless, in our experience it serves as an excellent opportunity for conversation and education. Students, many of whom have aspirations beyond their undergraduate studies, are often taken aback and embarrassed by the discovery. We approach this as an opportunity for them to reflect upon what this online behaviour may convey to an employer or professional/graduate degree program admission panel and to discuss the importance of acting with integrity in academics and beyond. Through these conversations, we have gained insight into the persistent marketing practices of these companies and their lucrative offers. In one case, a particularly prolific student contributor earned enough money to purchase a higher value laptop computer-all for sharing their personal sets of class notes. In all cases where we have been able to identify students, we have also asked them to request removal of posted material, which has occurred in all instances. Perhaps if a more concerted effort could be made across the country in the post-secondary sector, we would reduce the negative impact of these sites on academic integrity.

\section{Pandemic Challenge: Online Learning and the Use of Pay-To-Pass Sites}

With the rapid shift to online delivery of many courses due to the COVID-19 pandemic, there has been concern raised about observed increases in academic misconduct. In March 2020, educators worked quickly to redesign the delivery of the final weeks of their courses to offer them remotely. Since then, we and our colleagues across campus observed that this coincided with a marked jump in the number of academic misconduct cases, both reported and formally charged, over previous years. In large part, these cases were linked to pay-to-pass companies offering on-the-spot answers provided by their 'experts'. Indeed, this is comparable to the trend observed across Canada and around the world (Isai, 2020). With continued offering of online courses as a consequence of concerns due to the COVID-19 pandemic, the number of academic misconduct cases related to pay-to-pass companies now make up the majority of cases being reported for investigation. In one faculty at the University of Calgary, the number of academic misconduct cases related to Chegg and similar companies has risen from one or two cases per term to hundreds. While in the past we observed students finding or posting answers related to assignments and labs, it 
is now being observed that test questions are being posted (and answers received) in real time during the writing of tests (Isai, 2020). These companies are becoming so efficient at responding to posted questions that there have been cases where a student has uploaded questions during the writing of a quiz and received an 'expert' solution in under $15 \mathrm{~min}$, allowing the student to submit the work for credit.

Prior to the COVID-19 pandemic, the majority of students at the University of Calgary had little to no experience with online courses. For the 2020-2021 academic year, the majority of courses were offered remotely. Although some students flourished with this new mode of delivery, and had adequate support structures, many students struggled with the self-discipline and time management skills required for remote learning. Students have indicated that social isolation, job loss and emotional strain made it particularly challenging to study and meet deadlines. These factors have created an environment that makes students more vulnerable than normal to these companies. Companies promising 'faster homework solutions' and 24/7 access to and support from experts are alluring to students who are struggling. Although academic misconduct cases in the past primarily consisted of unauthorized collaboration between students and the copying of answers from peers or older assessments, students recently under investigation for misconduct have claimed that it has been challenging to create the study groups that once helped them prosper and learn and they have been turning to these companies to fill this void.

\section{Pedagogical Practice to Reduce Impact of Sites}

The emergence and now widespread use of pay-to-pass websites among students points to the importance we must each place on reforming our pedagogical practice as it pertains to assessment design. A critical first step is to move away from the re-use of assessments (e.g., exams, labs, tests) across multiple terms. This can be challenging in circumstances where core material needs to be assessed and speaks more broadly for the need of a substantial shift in our approach to assessment design.

At our institution, this became abundantly evident in the weeks following the closure of our campus due to concerns for COVID-19. Many of the assessments used at the end of the Winter 2020 term, in the weeks after the pandemic was declared, were not redesigned for the unexpected shift to online delivery, leading to a spike in cases of academic misconduct. For many instructors, this brought to light for the first time the pervasive presence of pay-to-pass companies and their promises. It stimulated reflection and conversation within and across institutions and has led instructors to consider alternative ways of assessing student learning in a way that minimizes the likelihood of academic misconduct, or the usefulness of the instant 'experts' available on pay-to-pass websites. By way of example, one colleague piloted an exam that encouraged discussion and collaboration amongst students on breaks provided during the writing of their exam. In this, students wrote synchronously for a 20-min period, took a 20-min break, and repeated the sequence over a three-hour period. The instructor found that the marks for this exam were consistent with those 
received on 'pre-COVID' exams and, furthermore, assessment of individual student learning was not compromised. Other educators have integrated exam alternatives, such as summative projects that can be delivered in a variety of formats (e.g., YouTube video, animation, scrapbook) and that allow students to showcase their learning from the course. Not only does this approach reduce the likelihood of misconduct, but it also meets goals associated with Universal Design for Learning (La et al., 2018).

The late Tracey Bretag, a global leader in the area of academic integrity, identified that changes in assessment design alone are not a panacea for the rise in academic misconduct due to pay-to-pass websites and other digitally-based facilitation of cheating (Bretag, 2018). Lienack and Esparza (2018), who described a first-hand account of the impact of pay-to-pass sites on resource-sharing among students, created their own course-based study site to which both faculty and students provided content to aid learning, making it less tempting for students to visit thirdparty websites (Lieneck \& Esparza, 2018). Considered together, these initiatives, and others limited only by our creativity, have the potential to reduce or eliminate the value and impact that pay-to-pass vendors have on university students. Many others in this volume discuss assessment design, but also point to the role of educating students as to the value and sanctity of their personal information (Gray, 2022).

\section{A Three-Pronged Educational Approach to Student Integrity}

Dyer (2010) has proposed a three-pronged approach to addressing the challenges to academic integrity in the age of collaboration, including proactive, reactive and adaptive steps (Dyer, 2010), while Stoesz and Eaton propose a "multi-pronged, multistakeholder" approach to promoting a culture of academic integrity in universities (Stoesz \& Eaton, 2020). In this chapter, we elaborate upon Dyer's three-pronged approach, incorporating elements proposed by Stoesz and Eaton, to propose a strategy that can be implemented in the Canadian post-secondary context.

\section{Proactive}

Discussions of academic integrity need to occur long before students reach the postsecondary level; we need to be proactive in educating students, teachers and parents about academic integrity and pay-to-pass companies from the earliest levels of education. Promotion of academic integrity must be integrated into the curriculum starting throughout the K-12 level, setting the stage for more advanced discussion at the post-secondary level. Children and parents must understand the subtle differences between sites aimed at explaining concepts from those supporting inappropriate collusion and homework help. Messaging must be consistent and upholding and promoting academic integrity needs to be the norm and not the exception. In the 
post-secondary context, steps must be taken at the course, faculty and institutional levels to build a culture and model of academic integrity.

At the University of Calgary, proactive steps at the course level include such examples as having a statement of integrity on each assessment and, in some cases, requiring students to sign an acknowledgement that they understand the conditions of the assessment and promise to uphold principles of academic integrity during its completion. Other instructors have created course-specific modules that focus on academic integrity and the influence of pay-to-pass companies. The assessments associated with the module either contribute to the final grade or are a requirement for passing the course. The goal for the waiver, assessments, and modules is to educate students while holding them accountable should a violation of academic integrity take place.

Proactive educational approaches have also been used at the faculty-wide level. One faculty collaborated with the Student Success Centre at the University of Calgary to develop academic integrity modules for all first-year students in their faculty. University policies prevented the faculty from making the modules mandatory, as they had not been stipulated as degree requirements in the University's Academic Calendar. When pilots of these modules for incoming students in a number of faculties were launched, the participation rates were discouraging low (Lock et al., 2019). The faculty is now considering alternative approaches that might encourage enhanced participation with these modules. Most faculties include statements of academic integrity and explicit prohibiting of the sharing of course materials on course outlines with links to University statements and policies; however, this is by itself insufficient. Instructors not only need to draw students' attention to these statements but also embed opportunities for discussion about these pay-to-pass companies and highlight the importance of academic integrity throughout the course.

The Student Success Centre at the University of Calgary has created a series of interactive workshops available to all students, and commonly used in remediation for students identified to have breached the University's academic misconduct policy. These include sessions on plagiarism and strategies to avoid it, academic integrity in collaborating with peers, and steps to avoiding unintentional academic misconduct in online learning. The University of Calgary has also taken part in the International Day of Action Against Contract Cheating since 2017. This Day of Action began in Fall 2016 with 34 registered post-secondary institutions around the globe, including three Canadian institutions (Humber College, Humber Institute of Technology \& Advanced Learning, University of Waterloo). Participation in the Day of Action continues to grow. In the Fall 2020, 300 institutions participated, including postsecondary institutions and high schools as well as education-focused companies; close to 40 Canadian post-secondary institutions were among this group. Although this event primarily focuses on contract cheating, the University of Calgary and many other institutions have taken the opportunity to expand this day to include discussions of pay-to-pass companies.

Since 2017, the University of Calgary has extended the International Day of Action into an Academic Integrity Week. During this week, events and workshops are offered both to and by faculty and students, including those with a focus on 
predatory companies, promoting of academic integrity and highlighting the supports available to instructors and students. In 2019, students played a major role in the planning, promotion and the hosting of events on campus. Empowering students to be active participants in all stages is integral in creating and promoting a culture of academic integrity. These student ambassadors facilitated discussion and educated their peers in fun, relatable and engaging ways.

\section{Reactive}

Universities must have institutional policies and procedures that support academic integrity by articulating the nature and consequences of academic misconduct. They must set clear expectations and the associated consequences must be universally applied (Dyer, 2010). The associated processes for reporting and handling of violations of academic integrity must not only be straightforward and transparent, but they must provide faculty with the necessary tools to aid in the prevention, detection and reporting of these breaches. Many institutions, including the University of Calgary, have either created or updated their statements on academic integrity as well as updated academic misconduct policies and procedures in an effort to clarify and promote academic integrity while also reacting to the growing number of cases of academic misconduct arising due to pay-to-pass websites.

In a study examining academic integrity policies and procedures from 23 publicly-funded universities in Western Canada, Stoesz and Eaton discovered that "nearly all documents described outsourcing behaviour and categorized it most often as a form of plagiarism", but did not specifically articulate these behaviours with the terms 'contract cheating' or 'pay-to-pass' (Stoesz \& Eaton, 2020). While the University of Calgary policy neither addresses pay-to-pass companies nor contract cheating directly, the creation of Academic Integrity Week, an academic integrity website (https://www.ucalgary.ca/student-services/studentsuccess/learning/academic-integrity), and a website that specifically addresses the dangers of paying for academic support (https://ucalgary.ca/current-students/payingfor-academic-support) guides students to uphold academic integrity.

Given how pervasive these sites are in the post-secondary context in Canada and around the world, it may be more appropriate to consider a broader response. For example, post-secondary institutions in Manitoba, Canada block access to these sites on campus computer networks, advising students that the websites are in violation of the institutional academic integrity policy and re-directing them to academic integrity resources (Seeland et al., 2020); the University of Calgary has recently taken similar action. In the United States, educational publishers have successfully used judicial paths to be awarded injunctions against websites posting textbooks, test answers and solution manuals (Pearson, 2020), reflecting another avenue for addressing these websites. While in Australia, legislation is now in place outlawing the provision or advertisement of academic cheating services (Cracking down on Cheating at Universities, 2020; Government of Australia, 2020). Convictions under the law can result in 
jail time and/or fines up to AUS\$100,000 (CAD\$95,000). More widespread implementation of such efforts in other jurisdictions could reduce the pervasiveness of pay-to-pass websites in the post-secondary context.

\section{Adaptive}

In their analysis, Stoesz and Eaton (2020) found that many of the academic integrity policies at Western Canadian universities tended to describe a punitive approach to breaches of integrity rather than taking an education-first perspective. This is in contrast to what Griffith (2013) found regarding academic integrity on the websites of 22 publicly-funded universities in Ontario, which predominantly reported an educative approach (Griffith, 2013). Griffith (2013) remarked that for websites to be impactful, they had to be easy to navigate, visually striking and with a strong focus on student-centred language, including the use of the pronoun you when addressing the student. These sites also took an approach that students were visiting this website to become better-informed and that they were educating themselves on preventing misconduct as opposed to assuming that misconduct had already taken place.

An educational approach is important when working directly with students who have committed academic misconduct. At the University of Calgary, in the majority of first-time academic integrity violations a grade penalty is assigned on the specific assessment and the student is given the opportunity to attend educational workshops in lieu of disciplinary probation. To track academic integrity violations, a neutral administrative indicator is placed on the student's file (but does not appear on the transcript), allowing administrators to identify potential 'repeat offenders', while allowing those who have had only a single episode to complete their program, and seek employment or experiential learning placements, without bias. This indicator is removed upon graduation.

Conversations with students who have committed academic misconduct typically reflect on the root cause(s) of why the misconduct took place, how it undermines academic integrity, and ways to avoid it from happening in the future. When the misconduct involves pay-to-pass companies, the conversation expands to not only the impact on the individual's learning but on the learning of others as well. These conversations are invaluable for shifting attitudes in an individual but remain woefully inadequate as an approach to changing the culture campus-wide.

\section{Conclusion}

The ubiquitous infiltration of pay-to-pass websites into the post-secondary landscape, with the lure of information accessible to all, has created a new challenge for upholding a culture of academic integrity. With the emergence of these sites in recent years, compounded by the rapid transition to online learning around the globe, 
proactive, reactive and adaptive responses are urgently needed to address the impact of these sites on academic integrity. These responses include but go beyond the scope of post-secondary institutions, requiring conversations that must begin at the earliest levels of education, while more concerted responses at the provincial or national level are equally essential. This ongoing problem represent a sizeable challenge as we look to the future of learning with integrity.

\section{References}

Adams, S. (2021). This $\$ 12$ billion company is getting rich off students cheating their way through covid. Forbes. Retrieved February 26, 2021, from https://www.forbes.com/sites/susanadams/ 2021/01/28/this-12-billion-company-is-getting-rich-off-students-cheating-their-way-throughcovid/

Amigud, A., \& Lancaster, T. (2019). 246 reasons to cheat: An analysis of students reasons for seeking to outsource academic work. Computers \& Education, 134, 98-107. https://doi.org/10. 1016/j.compedu.2019.01.017

Bretag, T. (2018, April 26). Academic Integrity. Oxford Research Encyclopedia of Business and Management. https://doi.org/10.1093/acrefore/9780190224851.013.147

Clarke, R., \& Lancaster, T. (2006). Eliminating the successor to plagiarism: Identifying the usage of contract cheating sites. Paper presented at the Second International Plagiarism Conference, The Sage Gateshead, Tyne \& Wear, United Kingdom

Course Hero-Scholarships. (n.d.). Retrieved November 26, 2020, from https://www.coursehero. com/scholarships/

Cracking down on cheating at universities. (2020). https://www.theaustralian.com.au/news/lat est-news/new-laws-passed-could-see-cheaters-who-sell-services-to-university-students-jailed/ news-story/599e268e4e5ff39e0766544688274092

Chibry, N., \& Kurz, E.U. (2019, April). Pay-to-Pass: Knowledge as a Commodity [Paper presentation]. Canadian Symposium on Academic Integrity, Calgary, AB.

Dyer, K. (2010). Challenges of maintaining academic integrity in an age of collaboration, sharing and social networking. In Proceedings of TCC 2010 (pp. 168-195). TCCHawaii. Retrieved May 14, 2021 from https://www.learntechlib.org/p/43770/

Eaton, S. E., Chibry, N., Toye, M. A., \& Rossi, S. (2019). Interinstitutional perspectives on contract cheating: A qualitative narrative exploration from Canada. International Journal for Educational Integrity, 15(1), 1-17. https://doi.org/10.1007/s40979-019-0046-0

Government of Australia (2020). Tertiary Education Quality and Standards Agency Amendment (Prohibiting Academic Cheating Services) Bill 2019 (Australia) [Text]. Retrieved January 23, 2021, from https://www.aph.gov.au/Parliamentary_Business/Bills_Legislation/bd/bd1920a/20b d084

Government of Canada \& CRTC. (2020). Undertaking-File No.: 9109-2019-00522-Notesolution Inc. (OneClass) - Effective date of undertaking: 21 September 2020 [Undertakings]. https:// crtc.gc.ca/eng/archive/2020/ut200921.htm

Gray, B. C. (2022). Ethics, ed tech, and the rise of contract cheating. In S. E. Eaton \& J. Christensen Hughes (Eds.), Academic integrity in Canada: An enduring and essential challenge: Springer.

Griffith, J. (2013). Pedagogical or punitive?: The academic integrity websites of Ontario universities. Canadian Journal of Higher Education, 43(1), 1-22. https://doi.org/10.47678/cjhe.v43i1.2216

Harrison, D., Patch, A., McNally, D., \& Harris, L. (2020). Student and faculty perceptions of study helper websites: A new practice in collaborative cheating. Journal of Academic Ethics. https:// doi.org/10.1007/s10805-020-09373-2 
Help more students, earn extra income with Educator Exchange (Beta). (n.d.). Share Your Study Resources with Our Community to Support Student Learning and Make Extra Income. Retrieved November 26, 2020, from https://educators.coursehero.com/educator-exchange

How does the Better Grades Guarantee Work? (n.d.). Customer Support-Course Hero. Retrieved November 26, 2020, from https://support.coursehero.com/hc/en-us/articles/218756988-Howdoes-the-Better-Grades-Guarantee-Work-Isai

Isai, V. (2020). The COVID-19 pandemic is changing how students cheat-and get caught. National Observer. https://www.nationalobserver.com/2020/09/28/news/covid-19-pandemicchanging-how-students-cheat-and-get-caught

Kolowich, S. (2009). Course Hero or Course Villain? https://www.insidehighered.com/news/2009/ 10/06/course-hero-or-course-villain

La, H., Dyjur, P., \& Bair, H. (2018). Universal Design for Learning in Higher Education. University of Calgary Taylor Institute for Teaching and Learning. https://taylorinstitute.ucalgary.ca/resour ces/universal-design-learning-higher-education

Lancaster, T. (2018). Turnitin DrSarahEaton Just reading comments from essay mill marketers in a blackhat forum in preparation for a talk next week. They put the US in first place for essays orders (not surprising), with the UK and Canada equal in second place. Twitter. https://twitter. com/DrLancaster/status/1029014675198013440

Lederman, D. (2020). Course Hero Woos Professors. Inside Higher Ed. https://www.insidehighered. com/digital-learning/article/2020/02/19/course-hero-once-vilified-faculty-courts-professors-its

Lieneck, C., \& Esparza, S. (2018). Collaboration or collusion? The new era of commercial online resources for students in the digital age: an opinion piece. Internet Journal of Allied Health Sciences and Practice, 16(3). https://nsuworks.nova.edu/ijahsp/vol16/iss3/7

Lock, J., Schroeder, M., \& Eaton, S. E. (2019). Designing and implementing an online academic integrity tutorial: Identifying the challenges within a post-secondary context. The Journal of Educational Thought, 52(3), 193.

Mascarenhas, N. (2020). Course Hero, a profitable edtech unicorn, raises rare cash. TechCrunch. https://social.techcrunch.com/2020/08/26/course-hero-a-profitable-edtech-unicorn-raises-rarecash/

Nemers, H. (2014, April 8). Profs nervous after finding lecture notes online. Ryersonian. $\mathrm{Ca}$. https://ryersonian.ca/the-note-sharing-site-oneclass-allows-students-to-share-test-sol utions-and-lecture-notes-online-for-credits/

New policy for Acceptable Use of Electronic Resources and Information. (2019). News. https:// www.ucalgary.ca/news/new-policy-acceptable-use-electronic-resources-and-information

Park, C. (2003). In other (people's) words: Plagiarism by university students-literature and lessons. Assessment \& Evaluation in Higher Education, 28(5), 471-488. https://doi.org/10.1080/026029 30301677

Pearson. (2020). Educational Publishers Obtain Preliminary Injunction Against 231 Websites Illegally Selling Test Answers and Solution Manuals. Retrieved January 23, 2021, from https:// www.prnewswire.com/news-releases/educational-publishers-obtain-preliminary-injunction-aga inst-231-websites-illegally-selling-test-answers-and-solution-manuals-301177537.html

Purdue News Service (2019). The Purdue University Online Writing Lab and Chegg Partner to Make World-Class Writing Education Tools More Accessible. Retrieved November 26, 2020, from https://www.purdue.edu/newsroom/releases/2019/Q1/the-purdue-university-online-wri ting-lab-and-chegg-partner-to-make-world-class-writing-education-tools-more-accessible.html

Purdue professors criticize writing partnership with Chegg. (n.d.). Retrieved November 26, 2020, from https://www.insidehighered.com/news/2019/03/12/purdue-professors-criticize-writing-par tnership-chegg

Richardson, L. (2015). Performing the sharing economy. Geoforum, 67, 121-129. https://doi.org/ 10.1016/j.geoforum.2015.11.004

Rogerson, A. M., \& Basanta, G. (2016). Peer-to-peer file sharing and academic integrity in the internet age. In T. Bretag (Ed.), Handbook of Academic Integrity (pp. 273-285). Springer. https:// doi.org/10.1007/978-981-287-098-8_55 
Rogerson, A. M. (2014, June). Detecting the work of essay mills and file swapping sites: some clues they leave behind. Paper presented at the 6th International Integrity and Plagiarism Conference, Newcastle-on-Tyne, United Kingdom. https://www.ro.uow.edu.au/gsbpapers/434/

Seeland, J., Stoesz, B. M., \& Vogt, L. (2020). Preventing online shopping for completed assessments: Protecting students by blocking access to contract cheating websites on institutional networks. Canadian Perspectives on Academic Integrity, 3(1), 55-69. https://doi.org/10.11575/cpai.v3i1. 70256

Share Notes, Get Rewarded. (n.d.). OneClass. Retrieved November 21, 2020, from https://oneclass. com/perks.en.html

Statistics Canada (2019, October 29). Smartphone use and smartphone habits by gender and age group. https://www150.statcan.gc.ca/t1/tbl1/en/tv.action?pid=2210011501

Stoesz, B. M., \& Eaton, S. E. (2020). Academic integrity policies of publicly funded universities in Western Canada. Educational Policy, 0895904820983032. https://doi.org/10.1177/089590482 0983032

What is pay to pass? (2019). News. https://www.ucalgary.ca/news/what-pay-pass

Nancy Chibry, M.Sc. is the Associate Dean, Undergraduate Programs and Student Affairs in the Faculty of Science at the University of Calgary. She is a Senior Instructor in the Department of Mathematics and Statistics and has always had a passion for showing others the beauty and stories behind numbers. She has helped promote academic integrity amongst students and faculty by serving on various academic committees, presenting at various conferences and co-publishing in the International Journal for Educational Integrity. She takes a student-centered approach in her teaching and interactions with students. She believes that through better understanding of how and when students are learning, educators can play a key role in guiding students to uphold academic integrity.

Ebba U. Kurz, Ph.D. is the Associate Dean (Undergraduate Health and Science Education) and Director for the O'Brien Centre for the Bachelor of Health Sciences Program. She is also a Professor in the Department of Physiology and Pharmacology and member of the Charbonneau Cancer Institute in the Cumming School of Medicine at the University of Calgary. Dr. Kurz is a passionate educator, mentor and leader in teaching and learning at the University of Calgary. She works closely with undergraduate students to create learning experiences that help them to think critically and to integrate complex information, while also supporting them in developing core transferable skills in oral communication, teamwork and academic writing. Dr. Kurz has a particularly keen interest in academic integrity-both fostering a culture of integrity in the classroom as well as understanding the impact of pay-to-pass websites of student learning. For her work in teaching and learning, Dr. Kurz has been honoured with the Killam Award for Undergraduate Mentorship, the McCaig-Killam Teaching Award, the University of Calgary Teaching Award for Excellence in Educational Leadership and the Students' Union Teaching Excellence Award. 
Open Access This chapter is licensed under the terms of the Creative Commons Attribution 4.0 International License (http://creativecommons.org/licenses/by/4.0/), which permits use, sharing, adaptation, distribution and reproduction in any medium or format, as long as you give appropriate credit to the original author(s) and the source, provide a link to the Creative Commons license and indicate if changes were made.

The images or other third party material in this chapter are included in the chapter's Creative Commons license, unless indicated otherwise in a credit line to the material. If material is not included in the chapter's Creative Commons license and your intended use is not permitted by statutory regulation or exceeds the permitted use, you will need to obtain permission directly from the copyright holder.

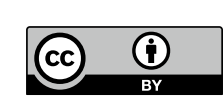

